\title{
Across-shift changes in upper airways after exposure to bacterial cell wall components
}

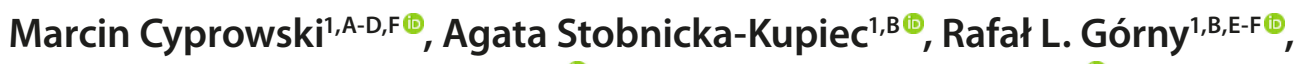 \\ Małgorzata Gołofit-Szymczak ${ }^{1, B \oplus}$, Aneta Ptak-Chmielewska ${ }^{2, C \oplus}$, Anna Ławniczek-Wałczyk ${ }^{1, B \oplus}$ \\ ${ }^{1}$ Depertment of Chemical, Aerosol and Biological Hazards, Central Institute for Labour Protection - National Research \\ Institute, Warsaw, Poland \\ 2 Institute of Statistics and Demography, Warsaw School of Economics, Warsaw, Poland \\ A - Research concept and design, B - Collection and/or assembly of data, C - Data analysis and interpretation, \\ $D$ - Writing the article, $E$ - Critical revision of the article, $F$ - Final approval of article
}

Cyprowski M, Stobnicka-Kupiec A, Górny RL, Gołofit-Szymczak M, Ptak-Chmielewska A, Ławniczek-Wałczyk A. Across-shift changes in upper airways after exposure to bacterial cell wall components. Ann Agric Environ Med. 2019; 26(2): 236-241. doi: 10.26444/aaem/106112

\begin{abstract}
Introduction. To assess the across-shift changes of cytokine concentrations in nasal lavage (NAL) samples were collected from workers exposed to bacterial cell wall components present in organic dust in three different occupational environments. Materials and method. The study was conducted in 38 employees including 10 workers from a municipal waste sorting plant (WSP), 20 from a sewage treatment plant (STP) and 8 from an office building (OB), who were established as a reference group, not exposed to organic dust. Interleukins $1 \beta$ (IL-1 $1 \beta), 6$ (IL-6), 8 (IL-8) and tumour necrosis factor alpha (TNF- $\alpha$ ) were examined in NAL before and after work shift on Wednesdays. Bioaerosol exposure was determined by personal measurements and analysed for organic dust, endotoxins (END) and peptidoglycans (PGN).

Results. The analysis included the results for IL-8 only, because for the other cytokines their concentrations in $80 \%$ of cases were below the detection level. The most polluted were the workplaces in WSP with average concentrations of organic dust $-3.47 \mathrm{mg} / \mathrm{m}^{3}$, END $-96.31 \mathrm{ng} / \mathrm{m}^{3}$ and PGN $-571.88 \mathrm{ng} / \mathrm{m}^{3}$. The results of IL-8 showed a significant difference between the studied groups after the work shift $(p=0.007)$. Among WSP workers concentrations of IL-8 increased also significantly $(p=0.015)$ during the work shift. Multivariate analysis showed that organic dust and END were the factors that in the most distinct way $(p<0.001)$ influenced changes of IL-8 levels in NAL.

Conclusions. Each alteration in the composition of bioaerosols will probably determine the changes in the mechanisms responsible for both formation and modulation of inflammatory reactions in exposed workers.
\end{abstract}

Key words

endotoxins, occupational exposure, IL-8, peptidoglycans, airway inflammation, across-shift changes

\section{INTRODUCTION}

Due to numerous studies conducted within last two decades, exposure to bioaerosols among waste management and sewage treatment plant workers has been quite well recognized $[1,2]$. Their occupational contact with biological agents (such as bacteria, fungi and their cell wall components including endotoxins (END) and ( $1 \rightarrow 3)-\beta$-D-glucans) may result in adverse health effects being, in the majority of cases, connected with respiratory tract infections, irritations, asthmatic reactions, or other lung function impairments (e.g. decrease of breathing effectiveness, etc.) $[3,4]$. In occupational exposure to biological aerosols, both endotoxins (END) and $(1 \rightarrow 3)-\beta$-D-glucans as highly conservative microbial structures (called pathogen-associated molecular patterns, PAMPs), being selectively recognizable by the immune system cells, can substantially modulate the host response [5]. Such stimulation usually results in increased production of cytokines including several interleukins (IL-1 $\beta$, IL-6, IL-8 or IL-12) and tumour necrosis factor alpha (TNF- $\alpha)[6,7,8]$. Untill now, however, the studies on cytokine levels released as a result of PAMPs stimulation among waste management

Address for correspondence: Marcin Cyprowski Depertment of Chemical, Aerosol and Biological Hazards, Central Institute for Labour Protection - National Research Institute, Poland

E-mail: macyp@o2.pl

Received: 24.03.2019; accepted: 01.04.2019; first published: 08.04.2019 and sewage treatment plant employees have not been very frequent and usually limited to nasal lavage (NAL) analyses $[9,10,11,12]$. Among them, only two performed acrossshift evaluation, where endotoxins, $(1 \rightarrow 3)-\beta$-D-glucans and organic dust were the main factors influencing the release of cytokines $[9,12]$. Such studies usually omit the role of other important immunologically-reactive factors such as peptidoglycans (PGN). These, being present in both Grampositive and Gram-negative bacterial cells, may synergistically interact with other PAMPs (e.g. endotoxins) [13]. However, the situation in which the presence of peptidoglycans significantly affects IL-6 concentrations was observed only in a pig farm environment [14]. To-date, such analyses have not been performed in other working environments.

The aim of this preliminary study was to assess the across-shift changes of cytokine concentrations in NAL samples collected from workers exposed to bacterial cell wall components present in organic dust in three different occupational environments.

\section{MATERIALS AND METHOD}

The study was conducted in 2014-2015 in three different workplaces: a municipal waste sorting plant (WSP), sewage treatment plant (STP) and an office building (OB). A total of 38 employees agreed to participate in the study: 10 workers 
from WSP, 20 from STP and 8 from OB, who were established as a reference group, not exposed to organic dust (Tab. 1). The average age of the workers was 49 years and period of employment in the current workplace was 9 years. All participants worked on a morning work shift from 07:0015:00, and the measurements were always carried out in the middle of the week (i.e. on Wednesdays).

Table 1. Description of population in the studied occupational environments

\begin{tabular}{lcccc}
\hline Parameter & OB & STP & WSP & Total \\
\hline Workers $(\mathrm{n})$ & 8 & 20 & 10 & 38 \\
\hline Gender, male $(\mathrm{n})$ & 4 & 13 & 4 & 21 \\
\hline Age (years) & 48 & 54 & 43 & 49 \\
\hline Current smoking $(\mathrm{n})^{*}$ & 0 & 2 & 2 & 4 \\
\hline Employment in studied plant (years) & 11 & 13 & 8 & 9 \\
\hline
\end{tabular}

OB - office building; STP - sewage treatment plant; WSP - waste sorting plant; * mean values

Bioaerosol samples were collected on GF/A glass fibre filters of $37 \mathrm{~mm}$ diameter (Whatman Inc., UK) using a Conical Inhalable Sampler (CIS) connected to an APEX aspirator (Casella Measurements Inc., UK). Sampling flow rate - 3.5 $\mathrm{L} / \mathrm{min}$. In order to remove the potential initial microbial contamination, before sampling, all filters underwent depyrogenation by high temperature $\left(180^{\circ} \mathrm{C}\right.$ for a minimum of 3 hours), and all sampling heads were washed in a $1 \%$ solution of E-Toxa-Clean fluid (Sigma-Aldrich, Poland). The sampling time was approx. 6 hours, i.e. covered of about $75 \%$ of the whole work shift time. After sampling, all filters were frozen at $-20^{\circ} \mathrm{C}$ until the analyses of endotoxins and peptidoglycans were performed. Endotoxins were assayed with the Limulus Amebocyte Lysate (LAL) test in its kinetic chromogenic version (Lonza Ltd., Switzerland) and peptidoglycans with a kinetic version of the Silkworm Larvae Plasma (SLP) test (Wako Pure Chemical Industries Ltd., Japan). Detailed description of analytical procedures has already been presented by Cyprowski et al. (2016). The activity of Escherichia coli 055:B5 standard endotoxin (CSE) was $7 \mathrm{EU} / \mathrm{ng}$. Both endotoxin and peptidoglycan concentrations were expressed in nanograms per cubic meter of sampled air $\left[\mathrm{ng} / \mathrm{m}^{3}\right]$.

Each time before and after the sampling, all filters were conditioned for $24 \mathrm{~h}$ in a microclimatic room at a mean temperature of $25.2^{\circ} \mathrm{C}$ (standard deviation, $\mathrm{SD}=0.26$ ) and in mean relative humidity of $40.6 \%(\mathrm{SD}=1.10)$ and weighed using microbalance (model ABJ 220-4M; Kern\&Sohn $\mathrm{GmbH}$, Germany) with the accuracy of $0.1 \mathrm{mg}$.

Nasal lavage (NAL) fluids were collected from employees before and after the work shift according to the modified method of Greiff et al. [15]. The sampling was performed in the presence of trained medical personnel using the Nasaline irrigator (Nasalprodukter Sverige AB, Sweden). In the case of each worker, a volume of $5 \mathrm{~mL}$ of $0.9 \%$ saline at room temperature was introduced with irrigator into its nostril and the obtained NAL fluid was collected into a sterile tube. The same procedure was repeated for the second nostril and the collected fluids were combined into one before their further analysis. All samples were transported within $8 \mathrm{~h}$ at $+4^{\circ} \mathrm{C}$ to the laboratory. The average recovery of NAL washings was $76 \%$. After measuring the volume, the obtained NAL fluids were subjected to centrifugation for $10 \mathrm{~min}$ at $1,200 \mathrm{rev} / \mathrm{min}$.
The collected supernatants were subsequently frozen at $-80^{\circ} \mathrm{C}$ in order to determine therein the concentrations of following cytokines: IL-1 $\beta$, IL-6, IL- 8 and TNF- $\alpha$.

This medical study was approved by the Bioethics Committee of the Nofer Institute of Occupational Medicine in Łódz, Poland (Resolution No. 4, dated 26 March 2014).

Interleukin analyses. For determination of cytokine concentrations (IL-1 $\beta$, IL-6, IL- 8 and TNF- $\alpha$ ) in NAL samples, the DuoSet enzyme linked immunosorbent assay (ELISA) kits (Human IL-1 $\beta$, Human IL-6, Human IL-8 and Human TNF- $\alpha$, were used, respectively; R\&D Systems, Inc., USA) were used according to manufacturer protocols. The applied analytical kits had the following quantification thresholds: IL-1 $\beta-0.58 \mathrm{pg} / \mathrm{mL}$, IL-6-0.54 pg/mL, IL-8-2.76 $\mathrm{pg} / \mathrm{mL}$, and TNF- $\alpha-0.45 \mathrm{pg} / \mathrm{mL}$.

Questionnaire survey. In order to identify the potential health effects of bioaerosol exposure among the examined workers, a health-based questionnaire was used [16, 17]. The questionnaire gathered, among others, information about the current occupational activities and workplace exposures, data regarding former workplaces and health hazards accompanying them, data on the hygienic conditions of the workplace, applied protection measures, sickness absence, addictions (e.g. tobacco smoking) etc. It also covered questions about health complaints reported by the workers, including 'flu-like' (fatigue, fever, chills, sweating, joints and muscles pain), 'respiratory' (dry cough, cough with phlegm, wheezing, shortness of breath, chest tightness), 'skin and mucous membranes irritation' (runny nose, throat irritation, nose irritation, eye irritation, itchy skin, skin rash), 'neurological' (headache, migraine, dizziness, difficulties in concentration) and 'gastrointestinal tract' (nausea, heartburn, loss of appetite, vomiting, diarrhea) symptoms, which were observed over the last year.

Statistical analysis. Multivariate analysis was performed using SAS statistical package (version 9.4, SAS Institute, Cary, USA). A total of 37 workers were included into the statistical analysis, as the failure of the measurement set was found in one employee of STP. The analysis included the results for IL- 8 only, as for the other cytokines (IL- $1 \beta$, IL- 6 and TNF- $\alpha$ ), their concentrations in NAL in $80 \%$ of cases were below the level of detection. In the case of IL- 8 , its concentrations below detection limit (11\% of the results) were replaced by values resulting from the statistical model. To assess the impact of working conditions characteristic for each studied group (i.e. OB, STP, WSP) on the release of IL-8, the measurements performed after the work shift were also taken into account. To evaluate the differences between these three occupational environments, the ANOVA analysis for not equal groups was applied. The raw data were not normally distributed; however, ANOVA is not sensitive to this assumption (which was confirmed when the variance homogeneity was tested). To analyse the influence of both exposure (e.g. organic dust, endotoxins and peptidoglycans) and control (smoking) factors, a generalized linear model (GLM) for the dependent variable (IL-8) was applied. To evaluate the relationships between exposure and reported symptoms, the Fisher test was used. In all models, the significance level was set at $\mathrm{p}<0.05$. 
Table 2. Concentrations of organic dust, endotoxins and peptidoglycans in the studied occupational environments

\begin{tabular}{|c|c|c|c|c|c|c|c|c|c|c|c|c|}
\hline \multirow{2}{*}{$\begin{array}{l}\text { Type of } \\
\text { workplace }\end{array}$} & \multicolumn{4}{|c|}{ Organic dust $\left[\mathrm{mg} / \mathrm{m}^{3}\right]$} & \multicolumn{4}{|c|}{ Endotoxins [ng/m³] } & \multicolumn{4}{|c|}{ Peptidoglycans [ng/m³] } \\
\hline & $\mathrm{AM}$ & SD & Range & CV & AM & SD & Range & CV & AM & SD & Range & CV \\
\hline $\mathrm{OB}$ & 0.14 & 0.13 & $0-0.40$ & 94.72 & 0.72 & 0.42 & $0.24-1.35$ & 58.11 & 112.36 & 92.85 & $6.86-280.63$ & 82.64 \\
\hline STP & 0.36 & 0.43 & $0-1.84$ & 119.04 & 5.03 & 6.01 & $0.21-19.13$ & 119.35 & 105.66 & 136.63 & $4.63-630.69$ & 129.30 \\
\hline WSP & 3.47 & 4.66 & $0.55-13.33$ & 134.24 & 96.31 & 162.49 & $9.30-548.35$ & 168.72 & 571.88 & 1426.96 & $52.19-4621.08$ & 249.52 \\
\hline
\end{tabular}

$\mathrm{OB}$ - office building; STP - sewage treatment plant; WSP - waste sorting plant; AM - arithmetic mean; SD - standard deviation; CV - variation coefficient; ns - not significant "Fisher test (ANOVA)

\section{RESULTS}

The measurements revealed a high difference in concentrations of organic dust, endotoxins and peptidoglycans among the studied occupational environments. The most polluted were the workplaces in WSP, where the average concentrations of the above-mentioned contaminants were $3.47 \mathrm{mg} / \mathrm{m}^{3}$, $96.31 \mathrm{ng} / \mathrm{m}^{3}$ and $571.88 \mathrm{ng} / \mathrm{m}^{3}$, respectively. The least contaminated by dust and endotoxins were the workplaces in the $\mathrm{OB}$, where their average concentrations reached $0.14 \mathrm{mg} / \mathrm{m}^{3}$ and $0.72 \mathrm{ng} / \mathrm{m}^{3}$, respectively. These differences between the examined plants were found to be statistically significant (Tab. 2). Regarding peptidoglycans, the lowest level of this pollutant was characteristic for workplaces in STP; however, this type of facility was not statistically different from $\mathrm{OB}$ and WSP. This study also revealed a significant correlations between endotoxin and organic dust concentrations $(\mathrm{r}=0.54 ; \mathrm{p}<0.001)$ (Tab. 3$)$.

Table 3. Spearman correlation coefficients for relationships between bioaerosol pollutant and IL-8 concentrations $(n=37)$

\begin{tabular}{lccc}
\hline & Organic dust & Endotoxins & Peptidoglycans \\
\hline Organic dust & & & \\
\hline Endotoxins & $0.54^{\#}$ & & \\
\hline Peptidoglycans & 0.01 & 0.28 & 0.04 \\
\hline IL-8 "after work shift" & $0.54^{\#}$ & $0.57^{\#}$ & \\
\hline${ }^{~} \mathrm{p}<0.001$ & & &
\end{tabular}

Analysis of IL-8 presence in NAL samples taken before the work shift showed that its average concentrations were practically on the same level among STP and WSP workers, and almost twice as high as those observed among $\mathrm{OB}$ employees (Tab. 4); however, due to the wide range of measured values, the difference between the studied groups of workplaces was not statistically significant. In turn, the measurement performed at the end of the work shift showed such a difference with a high statistical power (ANOVA: $\mathrm{F}=5.71 ; \mathrm{p}=0.007)$. In the case of both $\mathrm{OB}$ and WSP workers, the concentrations of this cytokine increased during the work shift; however, this augmentation was statistically significant only among WSP workers $(\mathrm{p}=0.015)$. Moreover, it was observed that the IL-8 "after work shift" levels significantly correlated with the concentrations of organic dust $(r=0.54$; $\mathrm{p}<0.001)$ and endotoxins $(\mathrm{r}=0.57, \mathrm{p}<0.001)$; however, no such relationship was found for peptidoglycan concentrations (Tab. 3).

Multivariate analysis of the results performed using a generalized linear model (Tab. 5) showed that all studied exposure factors significantly influenced the IL-8 concentrations in the NAL samples collected after the work shift. The inclusion of smoking habit as a disturbing factor into this analysis slightly modified the direction and strength of this phenomenon. As shown, in the examined group of 37 workers, both organic dust and bacterial endotoxins were the factors that in the most distinct way $(\mathrm{p}<0.001)$ influenced the changes of IL-8 levels in NAL fluids (with

Table 5. Relationships (based on generalized linear model, GLM) between factors of exposure and IL- 8 concentrations, taking into account smoking habit among studied workers

\begin{tabular}{|c|c|c|c|c|}
\hline \multirow[b]{2}{*}{ Exposure factor } & \multicolumn{4}{|c|}{ IL-8 "after work shift" } \\
\hline & Parameter & Exp(parameter) & Chi-square Wald & $\mathrm{p}$-value \\
\hline & \multicolumn{4}{|c|}{ Not adjusted for smoking } \\
\hline Organic dust & 0.85 & 2.33 & 24.42 & $<0.001$ \\
\hline Endotoxins & -0.02 & 0.98 & 20.88 & $<0.001$ \\
\hline \multirow[t]{2}{*}{ Peptidoglycans } & -0.001 & 0.99 & 20.21 & $<0.001$ \\
\hline & \multicolumn{4}{|c|}{ Adjusted for smoking } \\
\hline Organic dust & 0.79 & 2.20 & 28.29 & $<0.001$ \\
\hline Endotoxins & -0.01 & 0.99 & 12.25 & $<0.001$ \\
\hline Peptidoglycans & 0.002 & 1.00 & 0.45 & ns \\
\hline $\begin{array}{l}\text { Smoking }(\mathrm{N})^{*} \\
\text { Organic dust }\end{array}$ & -0.21 & 0.81 & 0.15 & ns \\
\hline $\begin{array}{l}\text { Smoking }(\mathrm{N})^{*} \\
\text { Endotoxins }\end{array}$ & 0.0001 & 1.00 & 0.00 & ns \\
\hline $\begin{array}{l}\text { Smoking }(\mathrm{N})^{*} \\
\text { Peptidoglycans }\end{array}$ & -0.003 & 0.99 & 0.82 & ns \\
\hline
\end{tabular}

ns - not significant

Table 4. Interleukin 8 (IL-8) concentrations in NAL samples from studied workers

\begin{tabular}{|c|c|c|c|c|c|c|c|c|c|c|}
\hline \multirow{2}{*}{ IL-8 (pg/mL) } & \multicolumn{5}{|c|}{ Before work shift } & \multicolumn{5}{|c|}{ After work shift } \\
\hline & Mean & $S D$ & Range & $C V$ & $F, p$ & Mean & $S D$ & Range & $C V$ & $F, p$ \\
\hline OB & 53.86 & 64.10 & $0.04-181.89$ & 119.03 & \multirow{3}{*}{$\mathrm{F}=1.32, \mathrm{~ns}$} & 64.24 & 89.08 & $0.04-265.04$ & 138.67 & \multirow{3}{*}{$\begin{array}{l}F=5.71, \\
p=0.007\end{array}$} \\
\hline STP & 106.78 & 152.06 & $0.04-679.36$ & 142.40 & & 86.78 & 87.80 & $0.04-375.27$ & 101.17 & \\
\hline WSP & 106.56 & 93.17 & $0.03-267.84$ & 87.44 & & $185.43^{*}$ & 78.47 & $75.65-284.65$ & 42.31 & \\
\hline
\end{tabular}

$\mathrm{OB}$ - office building; STP - sewage treatment plant; WSP - waste sorting plant; SD - standard deviation; CV - variation coefficient;

$\mathrm{F}$ - Fisher test (ANOVA); ns - not significant

${ }^{*} \mathrm{p}=0.015$ ( $t$-test for dependent variables) 
the proviso that the presence of organic dust contributed to a slight increase, while endotoxin to small decrease in the concentration of this inflammatory mediator). In the case of peptidoglycans, taking into account the smoking habit of the studied workers, such an impact ceased to be significant; however, the direction of this influence changed to a positive one. Nevertheless, it should be noted that such exposure to bacterial cell wall components in a similar way affected both smokers and non-smokers, as there were no statistically significant differences between these two groups.

Analysis of the questionnaire data revealed that among the most frequently reported complaints by the workers were: fatigue (percentage of positive answers - 43\%), eye irritation (24\%), throat irritation (24\%), nose irritation (16\%), joint and/or muscle pains (16\%) and dry cough (14\%). The analysis showed that only in the case of fatigue $(\mathrm{p}=0.017)$ and throat irritation $(\mathrm{p}=0.047)$, there were significant differences between the studied groups of employees. The statistical inference did not allow linking the reported health problems with a specific exposure factor; however, throat irritation was reported only by STP and WSP workers.

\section{DISCUSSION}

In this study, the authors attempted to analyse the presence of several cytokines in nasal lavage samples collected from workers across-shift exposed to bacterial cell wall components present in organic dust in three different occupational environments. The choice of worker groups was aimed to diversify the levels of bioaerosol exposure. It was shown that organic elements of dust, including bacterial cell wall components (i.e. endotoxins and peptidoglycans), were present in all three working environments; however, only in the waste sorting plant the levels of dust and endotoxins turned out to be significantly higher than in the other two studied workplaces. Moreover, the occurrence of inflammatory reactions in the upper respiratory tract, confirmed by a significant increase of interleukin 8 concentrations in NAL fluids after the work shift, was observed among the WSP workers only.

In the presented study, in none of the evaluated environments did the observed bioaerosol stimulation result in any increases in the concentrations of the other tested cytokines, i.e. IL-1 $\beta$, IL- 6 and TNF- $\alpha$. Such an observation is consistent with the findings of Wouters et al. [12], who studied a group of waste collectors. The results of the current study, however, differed from the observations regarding occupational exposure to swine dust. In such a polluted environment, in addition to the elevated levels of IL-8, an augmented concentrations of IL- 6 was more frequently observed $[14,18,19]$. Interleukin 6 was also the dominant cytokine in NAL samples collected from subjects exposed to poultry dust [20].

The concentrations of organic dust and endotoxins noted in the present study in the air of WSP were higher than those to which waste handlers were exposed [10], but comparable to those observed in the composting plant [9]. Similar to the results of the present study, in all these working environments, the increase of IL- 8 concentrations was clearly visible. On the other hand, there were no such relationships for workers in OB and STP, most probably due to significantly lower environmental concentrations of these exposure factors than those noted in WSP. Interestingly, a concentration decrease of this pro-inflammatory mediator in NAL samples was found only in the STP collected after a work shift. So far, there are no experimentally proven observations that could explain this phenomenon. On the one hand, some attention should be paid to the so-called "wash-out effect", which in organism of an exposed individual primarily affects the number of neutrophils, and can result in the reduction of cytokines up to $40 \%$ when across-shift changes in their levels are observed $[9,21]$. On the other hand, it can be related to the gender of the surveyed employees. In the current study, 35\% of STP employees were women. According to Hellgren et al. [22], in a group of workers exposed to soft paper dust, the IL- 8 concentrations in NAL samples collected from men was $46 \%$ higher than those obtained from women. A study carried out in several Swedish sewage treatment plants, although it did not analyse across-shift changes, revealed that the average IL- 8 concentrations in NAL from exposed STP workers (of which $10 \%$ were women) was $32 \%$ lower than in the control group [11]. Nevertheless, it seems that the largest impact on changes in the cytokine levels after exposure of the upper respiratory tract to bioaerosols, can be the organic dust itself, its origin and incompletely recognized chemical and biological composition.

Multivariate analysis of the results covering all three studied groups of workers showed that the presence of organic dust significantly contributed to the formation of inflammatory reactions in the upper respiratory tract (manifested in increased IL-8 concentrations), whereas endotoxins contributed to its slight decrease. Moreover, these relationships were so strong that they did not change after adjusting for the smoking habit. It is common knowledge that organic dust is a mixture of mineral (mainly silica), plant or animal epidermis particles, on the surfaces of which are transferred both viable and non-viable microorganisms, their fragments and toxins of microbial origin [23]. Therefore, its composition may vary, and together with that, its strength and scope of impact on the human body may be different. In an in-vitro study carried out by Hansen et al. [24], A549 epithelial cells were used to test the inflammatory potential of organic dust extracts of various origin based on cell ability to secrete IL-8. Analysing different variants, the researchers showed, among others, that the type of bacteria or fungi, as well as endotoxins and $(1 \rightarrow 3)-\beta$-D-glucans derived from them, increased the release of this interleukin. In addition, it was shown that the extracts from school dust had greater potential than the dust from waste composting plant and cotton dust. Also, the insoluble parts of the dust were several times more powerful than liquid extracts. These findings seem to correspond well with the results obtained by Cyprowski et al. [25], who analysed the exposure to $(1 \rightarrow 3)$ - $\beta$-D-glucans in composting and sewage treatment plants. They showed that the participation of water-soluble glucans among such particles present in organic dust from STP was about $25 \%$, while in the composting plant this percentage reached only $5 \%$. Although in the current study $(1 \rightarrow 3)-\beta-D$-glucan concentrations were not analysed, it is very likely that water-dust aerosols in STP may have a lower impact on the release of pro-inflammation markers than the dust aerosols present in WSP.

Multivariate analysis also showed that the influence of endotoxins on inflammatory reaction initiation in the present study revealed rather inversely proportional dependence, 
decreasing the release of interleukin 8 . Taking into account the results obtained by other researchers $[9,10,12]$, this might seem to be a surprising fact; however, in-vitro studies on epithelial cells performed by Allermann and Poulsen [26] showed a similar relationship. Also, Poole et al. [27] revealed that repeated exposure to organic dust causes the release of pro-inflammatory mediators by monocytes, regardless the endotoxin occurrence in the dust. In addition, it has been shown that the same organic dust may contribute to the release of anti-inflammatory cytokines, such as IL-10. These authors suggest that besides endotoxins, also other components of organic dust, such as peptidoglycans or solid mineral particles, may variously (i.e. synergistically or additively) effect inflammatory reactions.

In the presented study, the peptidoglycans (until now, a rarely studied element of bioaerosols) have been also taken into account. It was shown that their highest concentrations (mean - $571.88 \mathrm{ng} / \mathrm{m}^{3}$, range: $52.19-4621.08 \mathrm{ng} / \mathrm{m}^{3}$ ) were noted in WSP; however, they were lower than those found in the waste sorting plant or in a granary in Finland [28] and on pig farms in Sweden [14, 19]. So far, the use of peptidoglycans (determined using the SLP test) as a marker of bacterial contamination has been successfully proven in an oil mist environment [29]; however, to-date, no attempt has been to assess their impact on the respiratory system after exposure to bioaerosols. Despite their high concentrations at workplaces, in the presented study it was not possible to link firmly their environmental occurrence with cytokine concentration changes in NAL samples. Until now, only Zhiping et al. [14], when examining the serum of healthy people exposed to swine dust, showed significant relationships between PGN concentrations and the increase in IL- 6 levels. In other occupational environments, such relationships have not yet been identified.

The analyses performed in the current study revealed a statistically significant relationship between PGN and IL-8 only in the situation in which the smoking addiction of workers was not taken into account. There is no doubt that tobacco smoking is an important disruptive factor in this type of research, but other factors may also be responsible for the lack of significant dependencies. For example, in the above-mentioned study by Zhiping et al. [14], the exposure to peptidoglycans was assessed using a muramic acid as its marker. Also, recent reports suggest that the SLP test should be used with caution as it can give the "false-positive results" contributing to overestimation of the real exposure [30].

Taking the above into account, it should be clearly stated that the results of the current study are of a preliminary character. The authors are aware of numerous limitations connected with the number of exposure factors studied at selected workplaces, number of employees participated in the study, specificity of studied cytokines in NAL samples, spectrum of adverse health outcomes considered in questionnaire study, etc. Nevertheless, in the light of available scientific data, this study expands our knowledge about the effects of bioaerosol exposure underlying the important role of airborne bacterial cell wall components in the immunological stimulation of the upper respiratory tract.

\section{CONCLUSIONS}

In conclusion, it can be stated that the type and extent of release of pro-inflammatory mediators in the nasal airways is affected by a (specific for the environment) mixture of biological agents. Each alteration in the composition of bioaerosols will probably determine the changes in the mechanisms responsible for both the formation and modulation of inflammatory reactions in exposed workers. However, further studies of these processes are needed for confirmation which should take into account other occupational environments and different groups of workers exposed to different contaminants of microbial origin.

\section{Acknowledgements}

This study is based on the results of Research Task No. II.P.17 carried out within the scope of the third stage of the National Programme "Improvement of safety and working conditions", partly supported in 2014-2016 - within the scope of research and development - by the Ministry of Science and Higher Education/National Centre for Research and Development in Warsaw, Poland. The Central Institute for Labour Protection/National Research Institute is the main co-ordinator of the programme.

\section{Conflict of interest}

The authors declare they have no competing/conflicting interests in relation to the issues raised in this study.

\section{REFERENCES}

1. Gilbert Y, Duchaine C. Bioaerosols in industrial environments: a review. Can J Civ Eng. 2009; 36: 1873-1886.

2. Searl A, Crawford J. Review of health risks for workers in the waste and recycling industry. 2012, Institute of Occupational Medicine, London.

3. Poole CJM, Basu S. Systematic Review: Occupational illness in the waste and recycling sector. Occup Med (Lond). 2017; 67: 626-636.

4. Thorn J, Kerekes E. Health effects among employees in sewage treatment plants: A literature survey. Am J Ind Med. 2001; 40: 170-179.

5. Sigsgaard T, Bonefeld-Jorgensen EC, Hoffmann H.J., et al. Microbial cell wall agents as an occupational hazard. Toxicol Appl Pharmacol. 2005; 207: S310-319.

6. Akramiene D, Kondrotas A, Didziapetriene J, et al. Effects of betaglucans on the immune system. Medicina (Kaunas). 2007; 43: 597-606.

7. Liebers V, Raulf-Heimsoth M, Brüning T. Health effects due to endotoxin inhalation (review). Arch Toxicol. 2008; 82: 203-210.

8. Myhre AE, Aasen AO, Thiemermann C, et al. Peptidoglycan - an endotoxin in its own right? Shock. 2006; 25: 227-235.

9. Douwes J, Wouters I, Dubbeld H, et al. Upper airway inflammation assessed by nasal lavage in compost workers: a relation with bio-aerosol exposure. Am J Ind Med. 2000; 37: 459-468.

10. Heldal KK, Halstensen AS, Thorn J, et al. Upper airway inflammation in waste handlers exposed to bioaerosols. Occup Environ Med. 2003; 60: 444-450.

11. Thorn J, Beijer L. Work-related symptoms and inflammation among sewage plant operatives. Int J Occup Environ Health. 2004; 10: 84-89.

12. Wouters IM, Hilhorst SKM, Kleppe P, et al. Upper airway inflammation and respiratory symptoms in domestic waste collectors. Occup Environ Med. 2002; 59: 106-112.

13. Henne E, Campbell WH, Carlson E. Toxic shock syndrome toxin-1 enhances synthesis of endotoxin-induced tumor necrosis factor in mice. Infect Immun. 1991; 59: 2929-2933.

14. Zhiping W, Malmberg P, Larsson BM, et al. Exposure to bacteria in swine-house dust and acute inflammatory reactions in humans. Am J Respir Crit Care Med. 1996; 154: 1261-1266.

15. Greiff L, Meyer P, Svensson C, et al. The "nasal pool"- device for challenge and lavage of the nasal mucosa in children: histamine- 
induced plasma exudation responses Pediatr Allergy Immunol. 1997; 8: $137-142$.

16. Krajewski JA, Cyprowski M, Szymczak W, et al. Health complaints from workplace exposure to bioaerosols: a questionnaire study in sewage workers. Ann Agric Environ Med. 2004; 11: 199-204.

17. Rylander R, Peterson Y, Donham KJ. Questionnaire evaluating organic dust exposure. Am J Ind Med. 1990; 17: 121-126.

18. Larsson BM, Palmberg L, Malmberg PO, et al. Effect of exposure to swine dust on levels of IL-8 in airway lavage fluid. Thorax. 1997; 52: 638-342.

19. Wang Z, Larsson K, Palmberg L, et al. Inhalation of swine dust induces cytokine release in the upper and lower airways. Eur Resp J. 1997; 10: 381-387.

20. Larsson BM, Larsson K, Malmberg P, et al. Airway responses in naive subjects to exposure in poultry houses: comparison between cage rearing system and alternative rearing system for laying hens. Am J Ind Med. 1999; 35: 142-149.

21. Houser R, Kelsey KT, Christiani DC. Variability of nasal lavage polymorphonuclear leucocyte counts in unexposed subjects: its potential utility for epidemiology. Arch Environ Health. 1994; 49: $267-272$.

22. Hellgren J, Eriksson C, Karlson G, et al. Nasal symptoms among workers exposed to soft paper dust. Int Arch Occup Environ Health. 2001; 74: $129-132$
23. Rylander R, Jacobs RR. Organic dusts exposure, effects, and prevention. 1994, CRC Press, Boca Raton.

24. Hansen LA, Poulsen OM, Nexø BA. Inflammatory potential of organic dust components and chemicals measured by IL- 8 secretion from human epithelial cell line A549 in vitro. Ann Agric Environ Med. 1997; 4: 27-33.

25. Cyprowski M, Sowiak M, Szadkowska-Stańczyk I. $\beta(1 \rightarrow 3)$-glucan aerosols in different occupational environments. Aerobiologia. 2011; 27: 345-351.

26. Allermann L, Poulsen OM. Inflammatory potential of dust from waste handling facilities measured as IL-8 secretion from lung epithelial cells In Vitro. Ann Occup Hyg. 2000; 44: 259-269.

27. Poole JA, Wyatt TA, Von Essen SG, et al. Repeat organic dust exposureinduced monocyte inflammation is associated with protein kinase $\mathrm{C}$ activity. J Allergy Clin Immunol. 2007; 120: 366-373.

28. Laitinen S, Kangas J, Husman K, et al. Evaluation of exposure to airborne bacterial endotoxins and peptidoglycans in selected work environments. Ann Agric Environ Med. 2001; 8: 213-219.

29. Cyprowski M, Ławniczek-Wałczyk A, Górny RL. Airborne peptidoglycans as a supporting indicator of bacterial contamination in a metal processing plant. Int J Occup Med Environ Health. 2016; 29: 427-437.

30. Ma M, Rice TA, Percopo CM, et al. Silkworm larvae plasma (SLP) assay for detection of bacteria: False positives secondary to inflammation in vitro. J Microbiol Methods. 2017; 132: 9-13.

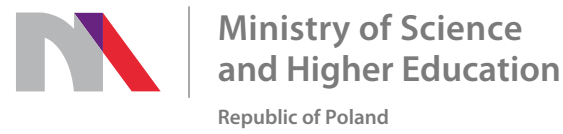

Generation of the DOI (Digital Object Identifier) - task financed under the agreement No. 618/P-DUN/2019 by the Minister of Science and Higher Education 